\title{
An Empirical Study of Spatial-Temporal Growth Patterns of a Voluntary Residential Green Infrastructure Program
}

\author{
THEODORE C LIM \\ Penn Institute for Urban Research, University of Pennsylvania \\ tlim@upenn.edu
}

\section{ABSTRACT}

Voluntary residential Green Infrastructure (GI) stormwater management retrofit programs can help cities comply with environmental regulations while also improving quality of life. Previous research has identified influential factors in residents' willingness to adopt GI, but few have simultaneously studied the spatial and temporal dynamics of GI. I use a six-year record of participation in a voluntary residential GI program in Washington DC to explore how neighborhood characteristics and social influence affect GI adoption over time. Statistical regression and Monte Carlo permutation resampling techniques are used to explain the spatial-temporal patterns of growth of the program. I demonstrate empirical evidence that participation location is increasingly determined by the locations of previous participants. These findings suggest that past participants will increasingly influence spatial clustering of GI in the city.

\section{KEYWORDS}

Green Infrastructure, Environmental Behavior, Residential Stormwater Management, Spatial-Temporal Patterns, Voluntary Participation

An edited version of this paper was published in the Journal of Environmental Planning and Management. Copyright (2018) Taylor and Francis. The article can be accessed at:

https:/doi.org/10.1080/09640568.2017.1350146

Suggested citation:

Lim, Theodore Chao. 2018. "An Empirical Study of Spatial-Temporal Growth Patterns of a Voluntary Residential Green Infrastructure Program." Journal of Environmental Planning and Management 61 (8): 1363-82. https://doi.org/10.1080/09640568.2017.1350146. 
Confidential manuscript in review at Journal of Environmental Planning and Management

\section{INTRODUCTION}

Over forty years after the US EPA's passage of the Clean Water Act (CWA), 53\% of river and stream miles and $69 \%$ of lakes, ponds and reservoirs in the US remain classified as "impaired" (US EPA 2015). "Green Infrastructure" (GI) is a multi-scale strategy that acknowledges the critical roles natural processes such as evapotranspiration and infiltration play in supporting healthy, sustainable societies (Benedict and McMahon 2006). GI can be used to refer to the importance of regional scale conservation planning (e.g. riparian corridor protection and growth management) on hydrological regime and water quality. Within cities however, GI often refers to the implementation of best management practices (BMPs) for stormwater management. These BMPs include rain gardens, bioswales, porous pavement, and tree plantings. They are mean to bring cities into compliance with stormwater and sewage infrastructure CWA regulations while also improving overall environmental quality and livability and are often implemented at the site scale. This type of GI is implemented on a property-by-property basis, often by retrofitting sites to better manage stormwater runoff (US EPA 2004; Mandarano and Paulsen 2011; Young 2011).

Understanding how to encourage and speed private property retrofits is particularly useful for post-industrial cities, which are likely to have slow redevelopment rates, stagnated population growth, and aging infrastructure in need of upgrade (Birch and Wachter 2008; Schilling and Logan 2008)). Residential land use can make up over $50 \%$ of the land area in urbanized areas, making voluntary residential adoption of GI a potentially very cost effective means for cities to manage stormwater runoff, especially after ecosystem services co-benefits are factored in (Mandarano 2011; Brown et al. 2016). As I will expand on in the following section, previous research has explored the influence of financial incentives, environmental attitudes, environmental knowledge, and physical constraints on the potential for residential adoption of GI.

In this study, I examine the spatial-temporal patterns in which GI has actually been adopted by residents in Washington DC during the first six-years of a voluntary GI installation program called RiverSmart Homes. Unlike the results of surveys, in which residents are asked directly about willingness to participate based on their preferences, the analysis of empirical data adds two things. First, it illuminates how highly heterogeneous spatial distributions of physical and social factors have influenced actual adoption. Second, it allows us to explore the spatial implications of time-dependent processes of adoption, such as pathways of information dissemination. This research tests how participation is dependent on spatial distribution of socio-demographic and physical landscapes of the city and how the 


\begin{abstract}
Confidential manuscript in review at Journal of Environmental Planning and Management

spread of participation also exhibits a space-time event dependence that can be associated with the locations of previous installations.
\end{abstract}

\title{
2 PREVIOUS RESEARCH
}

Conventional drainage infrastructure, including catch basins, pipes and cisterns, is typically located in the public right of way. Retrofits of existing impervious areas with GI to effectively manage runoff close to where it is generated is often referred to as 'source control'. Source control measures, such as rain gardens, require land surface area to intercept and retain or detain runoff volumes (Valderrama and Levine 2012; Keeley et al. 2013). Access to these areas can be gained through new development regulations or through encouraging property owners to retrofit their properties. Localities with limited local budgets and slow redevelopment rates see GI as a cost-effective alternative to conventional infrastructure, especially if GI can be constructed by retrofitting private properties rather than relying on public property and right-of-way projects (Valderrama and Levine 2013).

Several studies have used surveys to determine the relationship between the residential uptake of GI and socio-demographic characteristics. Participants' stated responses reflect both public and private motivations to GI adoption. Stated public benefits include: general desire to improve the environment (Thurston et al. 2008; F. Montalto, Behr, and Yu 2012; Baptiste, Foley, and Smardon 2015), stormwater control (Sun and Hall 2013), better water quality and hydrological improvement (Londoño Cadavid and Ando 2013). Stated private benefits include: owners' desire to reduce personal property flooding (Londoño Cadavid and Ando 2013), financial savings when subsidized installations are offered (Brown et al. 2016), and access to an unregulated source of irrigation water (Brown et al. 2016). Although participant survey responses yield insight into individuals' preferences for environmental services, research has shown that actions can differ substantially from stated intentions (Diamond and Hausman 1994; Portney 1994).

One potential source of difference between stated responses and actual program participation is that responses to surveys reflect the respondent's preferences assuming he or she is aware of the program in question. In reality, awareness about voluntary programs may be a stronger determinant of participation. Many have suggested economic incentives as one way to increase awareness of strormwater management and encourage private adoption of GI. These incentives work through pricing the externality of runoff production and crediting property owners that treat or management their own stormwater runoff (Sample et al. 2003; Parikh et al. 2005). The logic of economic incentive strategies is based on an assumption of economic rationality where property owners will invest in GI construction if they can achieve long-term cost savings on stormwater fees. 


\section{Confidential manuscript in review at Journal of Environmental Planning and Management}

However most studies demonstrating the effectiveness of such approaches are theoretical rather than empirically-based. After taking into account the time that knowledge about fees, credits and GI retrofits takes to travels through social networks and individual decision-making processes, adoption rates have been shown to be much lower than when perfect economic rationality is assumed (F. A. Montalto et al. 2013).

Infrastructure managers have also reported that limited public knowledge about stormwater issues and lack of familiarity are barriers to widespread adoption of GI (de Graaf and der Brugge 2010; Keeley et al. 2013). Resident unfamiliarity with GI programs may also deter them from participation. Interviews carried out with participants in an economic-incentive based GI program confirmed that the decision to participate represented having taken a risk. In overcoming this risk, one third of interviewees expressed that "word-of-mouth" and "project presence" played a significant role in the decision to participate (Brown et al. 2016).

Few empirical studies address the spatial patterns of residential GI adoption. An empirical study of a subsidized, voluntary rain barrel program showed that adoption counts were related to the social characteristics of neighborhoods, including "green" party voter proportions and home ownership rates. In addition, this study showed higher adoption rates in locations nearer to rain barrel distribution sites and near long-term GI demonstration and information dissemination sites (Ando and Freitas 2011). Another study of a two-year experimental residential rain garden adoption program showed more spatial clustering near previous adopters than would have been expected due to chance accounting for the heterogeneity in the spatial configurations of parcels (Green et al. 2012). These studies reveal a move from static personal attributes as drivers of GI adoption towards understanding the influences of time-dependent information dissemination and social capital on GI adoption.

Yard landscaping practices have also been framed as expressions of personal preferences as well as functions of historical and modern social norms. Research shows that residents' yard landscaping practices are extensions of self-image that respond to cultural norms and that vegetation choices exhibit mimicry between neighbors (Zmyslony and Gagnon 1998; Larsen and Harlan 2006; Nassauer, Wang, and Dayrell 2009). Therefore, we might expect the participation of resident in a GI program to have some influence on his/her neighbors' propensity to participate in the program. Participation in a voluntary GI program may similarly be socially influenced since it reflect both landscaping preferences and requires residents to gain awareness of the program. Gaining awareness of the program itself is a process of information dissemination. Others have suggested "epidemic" models of technology diffusion to express the spread of new information (Geroski 2000; Jaffe, Newell, and Stavins 2002). In these models, imitative behavior is primarily 


\begin{abstract}
Confidential manuscript in review at Journal of Environmental Planning and Management

influenced by the spread of information through proximity-dependent social networks. Empirical research has demonstrated the utility of information dissemination models for explaining highly visible behaviors, such as residential solar panel installation (Rode and Weber 2016), automobile purchasing (Grinblatt, Keloharju, and Ikaheimo 2004), and recycling (Hopper and Nielsen 1991). When neighbors are exposed to "nudging" information, even a non-visible environmental behavior, such as energy and water consumption has been shown to be influenced by neighbors' behaviors (Allcott 2011; Jain et al. 2013). Normative social influence, which relies not only on sharing of information, but also on communication of behavioral standards ("the right thing to do"), has been shown to be influential, even if residents do not report it being a major rationale for behavioral change (Nolan et al. 2008; Schultz et al. 2016).
\end{abstract}

From the above, we can hypothesize two major causes of observed spatial patterning of voluntary GI. First, adoption rates may be determined by the spatial heterogeneity of social and physical conditions with the city. Second, the locations of participants may be determined by time-dependent information diffusion, which may influence spatial clustering of adoption. In the latter, emphasis is shifted from the physical and social conditions that drive residents to independently adopt GI towards understanding how residents learn about the program and subsequently decide to participate. If participation locations are dependent on the spatial locations of previous GI installations, even after controlling for the tendency of properties and residents with similar characteristics to cluster together, this is evidence of previously uncaptured spatial processes of program growth. Understanding the spatial-temporal growth of voluntary GI programs can help urban watershed managers who leverage ambassadorial behaviors or key demonstration sites in residential areas to efficiently disseminate information that promotes residential participation in environmental programs (Hopper and Nielsen 1991; Castaneda et al. 2015). This is important because if previous installations and participants influence the participation of their neighbors, municipalities might anticipate savings on future outreach budgets and plan for when a program may begin to grow on its own. Quantifying this type of influence also begins to suggest the range of timeframe necessary for adapting urban landscapes to future conditions through private landscape management.

\title{
3 CASE STUDY: WASHINGTON DC RIVERSMART HOMES PROGRAM
}

\subsection{PROGRAM DESCRIPTION}

The case used in this research is the RiverSmart Homes Program, administered by Washington DC's Department of Energy and the Environment (DOEE). RiverSmart 


\section{Confidential manuscript in review at Journal of Environmental Planning and Management}

Homes is a voluntary stormwater retrofit program that provides subsidized installations of GI to residents. The purpose of the program is to help residents reduce stormwater runoff from their properties. It offers subsidies to adopt rain barrels, rain gardens, bayscaping (native plant landscaping), permeable pavement or shade trees on their properties. Homeowners make a copayment for each of the installations: $\$ 45$ per rain barrel, $\$ 50$ per shade tree, $\$ 75$ per rain garden (limit one), $\$ 100$ per bayscaping installation (limit one), and up to $\$ 1200$ for the removal of impervious surface area and installation of permeable pavers. Participants are informed that they are required to maintain the installed features while they own the property.

The process of becoming a RiverSmart Homes participant involves the resident finding out about the program, contacting RiverSmart Homes staff to schedule an initial appointment (usually through an online scheduler) to assess which installations would be feasible on the property, deciding which type of GI is desired (if any), scheduling a contractor to install the GI and lastly installing the GI. The DOEE completes about 1,100 audits each year. Based on pilot programs administered by DOEE starting in 2007, DOEE specifically sought to eliminate barriers to participation including inability for non-car owners to transport materials to their homes, lack of understanding about installation and maintenance of GI (DC Water 2015). Project funding has been provided through EPA 319 grants, American Recovery and Reinvestment Act funds, the Anacostia River Clean Up and Protection Fund, and Municipal Separated Sewer System (MS4) funds (DC Water 2015). The geospatial location for each RiverSmart homes installation was recorded between 2009-2015. Dates of adoption for each participant are also available. Figure 1 shows the overall participation trend over time. Through 2014, there were 3,737 RiverSmart Homes installations on 2,836 unique properties, which represents 2.5 percent of all residential parcels in DC. The most popular installation was rain barrels (63\%), followed by bayscaping (17\%), rain gardens (14\%), and lastly trees and permeable pavers (3\% each). Figure 2 shows a map of the density of all GI installations through the RiverSmart Homes Program, overlaid on total populations of each of the district's census tracts. It is clear that there is spatial clustering of adoptions within the city.

In 2014, DOEE administered an online survey (>800 responses) of participants' experiences with their GI installations. The survey included a question asking participants how they initially learned about the RiverSmart Homes program. Figure 3 shows that the majority of respondents learned of the program through friends, family or a past participant. What remains unknown is the extent to which these informational networks resulted in spatial patterns. 
Confidential manuscript in review at Journal of Environmental Planning and Management

\section{Program Participation}

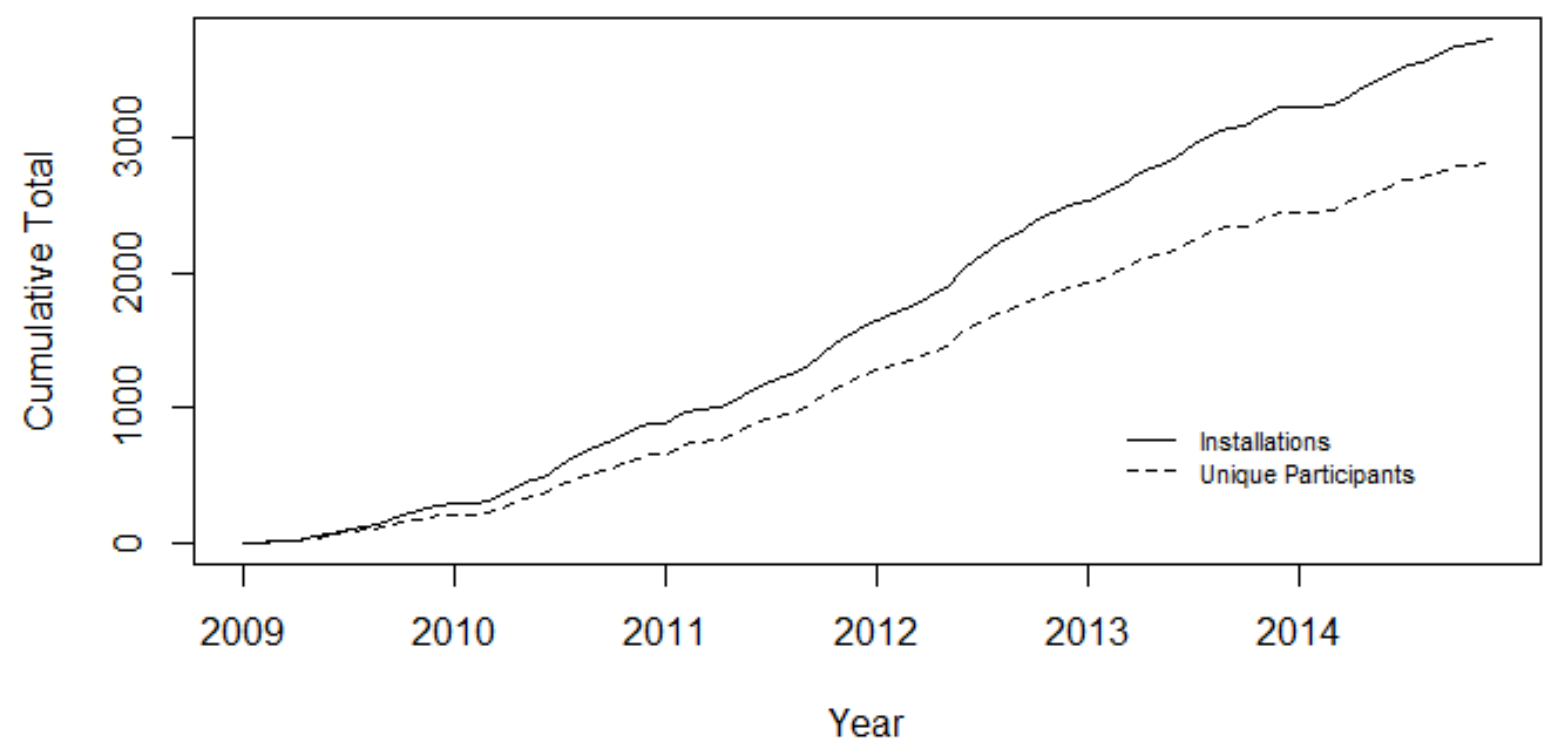

Figure 1. Cumulative number of installation and program participants over time 
Confidential manuscript in review at Journal of Environmental Planning and Management

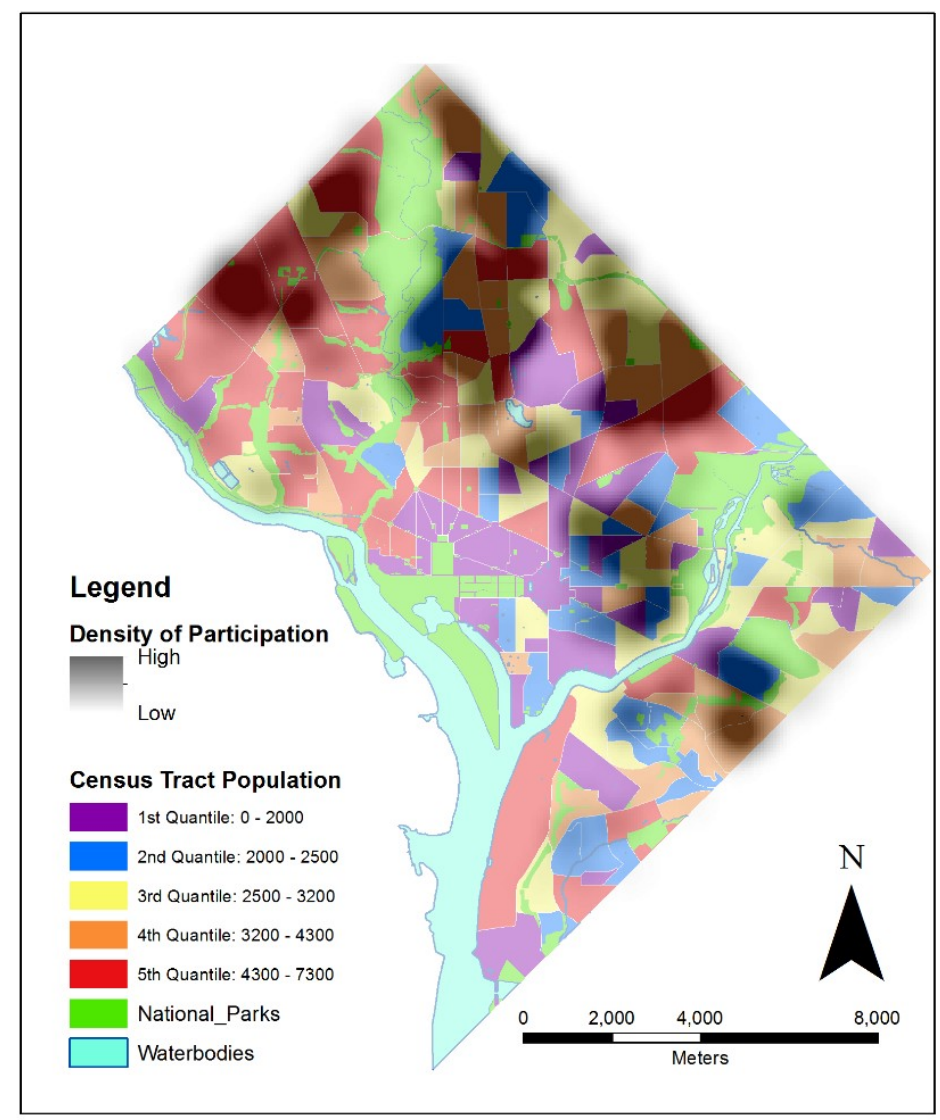

Figure 2. Density of all GI installations through the RiverSmart Homes Program from 2009 - 2014, overlaid on total population per census tract. 
Confidential manuscript in review at Journal of Environmental Planning and Management

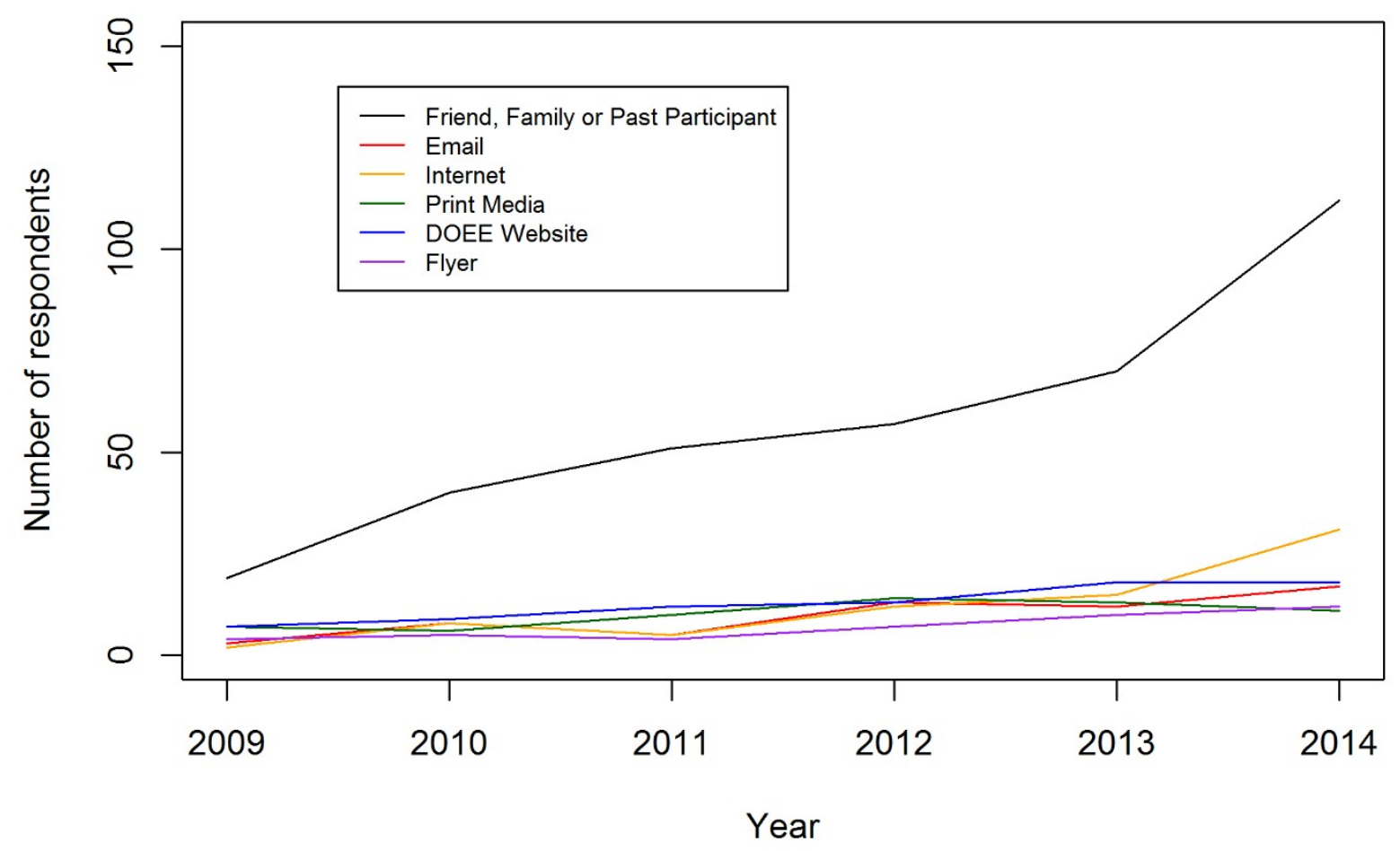

Figure 3. Survey responses from RiverSmart Homes participants to how they initially learned of the program.

\section{METHODS}

\subsection{OVERALL ADOPTION RATE REGRESSION}

The regression of overall adoption rates between 2009 - 2014 on neighborhood characteristics captures the effects of spatially-dependent factors that influenced early residential GI adoption. Previous literature indicates that both physical form and social characteristics of neighborhoods are likely to reflect information dissemination and landscaping preferences. Therefore, two sets of explanatory variables, for physical and demographic neighborhood characteristics are included. The regression is specified as in Equation 1.

$\log \left(\right.$ GIcount $\left._{i}\right)=\alpha+\delta \log \left(\right.$ toth $\left._{i}\right)+D_{i} \beta+P_{i} \gamma+u_{i}$

where $\log \left(\right.$ GIcount $\left._{i}\right)$ is the log of the total number of GI installations for census tract $i ; \log \left(\right.$ toth $\left._{i}\right)$ is the log of the total number of households in census tract $i ; D_{i}$ is a vector of census tract $i$ 's demographic variables and $P_{i}$ is a vector of census tract $i$ 


\section{Confidential manuscript in review at Journal of Environmental Planning and Management}

's physical variables. Nested models of the full global model presented in (1) were estimated to compare the explanatory power of the model with only physical variables $P_{i}$ (the global physical model) versus the model with only demographic variables $D_{i}$ (the global demographic model). The maximum likelihood ratio test was calculated on the ordinary least squares regressions to quantify the explanatory strength of the global physical and global demographic models. Variance Inflation Factors (VIFs) were also calculated to ensure that variables included in each model did not exhibit extreme multicollinearity, which could result in unreliable coefficient and standard error estimates.

Spatial autocorrelation, a violation of the ordinary least squares assumption that observations are independent and identically distributed, is a symptom of social influence, diffusion processes, and missing spatially correlated variables (Anselin and Griffith 1988). This problem has been shown to result in inaccurate (artificially low) measures of standard error associated with the estimated coefficients (Hoechle 2007). While the coefficient estimates themselves will not change, standardized coefficients, which are needed to draw conclusions about the explanatory strength of each of the variables included in the model will be influenced by mis-estimated standard errors. Calculation of Moran's I on the residuals for each model is a common methods of determining the extent to which the amount of variation in the data unexplained by the model may be biased due to uncaptured spatial autocorrelation.

To address this problem, the specification shown above was also used to estimate a Geographic weighted regression (GWR) on the standardized variables included in the full global model. GWR generalizes the assumptions that observations are independent and identically distributed, and is used to demonstrate extent of spatial variability of estimated coefficients between census tracts through distance-weighting the results of repeated regressions (Fotheringham, 2009). Through a cross-validation, leave-one-out technique a kernel weighted bandwidth is chosen to determine how spatially correlated coefficient estimates will be determined. Smaller bandwidths allow GWR coefficient estimates to be highly dependent on nearby neighbors' estimates and reflect high levels of spatial dependence (Bivand 2017). The selection procedure for the adaptive bandwidth and the GWR coefficient estimation were performed using the ' $R$ ' package 'spgwr'. The chosen kernel weighting scheme was based on a Gaussian distribution. One GWR model is fit for each of the 172 census tracts included in the study. An alpha $=0.05$ significance level determined the significance of each census tracts' GWRestimated standardized coefficients. The set of GWR model estimates are centered on the OLS regression (the full global model) estimates.

Linear regression was chosen to maintain interpretability of the estimated coefficients. The log transformation of the total count of GI installations aided in 


\begin{abstract}
Confidential manuscript in review at Journal of Environmental Planning and Management

ensuring a more normal distribution of residuals from the estimated models. The presence of GI adoptions was treated as latent propensity to adopt GI. To avoid biasing the model coefficients from removing zero-valued census tracts from the analysis however, these census tracts were assumed to have low propensity of adoption, and a small value (0.1) was added before taking the log. Theoretically, this treats number of adoptions per each census tract as a proxy for the latent propensity of residents within the census tract to participate in the program. Summary statistics for each type of GI and the attributes of the census tracts are shown in TABLE 1.
\end{abstract}

The explanatory variables included in the regressions were assembled from various sources and aggregated to the census tract level, which is a unit of analysis intended to act as a proxy for neighborhoods. Physical variables included: mean area of residential parcels, mean percent impervious of residential parcels, and mean tree canopy cover of impervious parcels. The mean area of residential parcels was calculated by selecting the properties with use code descriptions including the word "residential" (including: single family, multi-family, mixed use, etc) according to the Government of the District of Columbia Office of Tax and Revenue classifications (http://app.cfo.dc.gov/services/tax/property/pdf/usecodes.pdf) and the property lot shapefile from the District of Columbia Open Data portal (http://opendata.dc.gov/datasets/1f6708b1f3774306bef2fa81e612a725 40). The mean area of residential parcels per census tract was log transformed to correct for a right skewed distribution. The percent impervious and percent tree canopy were calculated using Zonal Statistics (ArcGIS Desktop 10.4) tools to summarize raster land use classification types per each residential property boundary. High resolution (1 meter x 1 meter) raster data classifying urban land cover in DC into six classes (base soil, buildings, roads/railways, other paved surfaces, tree canopy, and water) was obtained from the University of Vermont (University of Vermont 2011). Land cover for this dataset was derived using orthorectified leaf-on multispectral imagery. Each parcel's existing land cover percentages were aggregated to the census tract level by averaging percent tree canopy cover for all residential parcels in the census tract. Demographic variables included: median household income, percent renters in the census tract, percent non-English speaking population, population density, percent white, and median home value, among others. All demographic variables came from 2010 US Census. The distribution of each variable to be included was examined to limit the influence of skewed distributions and outliers. Median household income was log-transformed to correct the right-skewed distribution and percent white was represented as a dummy variable $(=1$ if $>80 \%$ white) because of a clear bimodal distribution in the data. The percent of the census tract in which English was not the primary household language was represented as a dummy variable ( $=1$ if $>0.3 \%$ ) to 


\section{Confidential manuscript in review at Journal of Environmental Planning and Management \\ capture the effect of long right tailed distribution. TABLE 1 shows summary statistics for each of the variables considered for the regression.}

\subsection{SHUFFLE TEST}

In order to test for evidence of spatial-temporal dependence of GI adoption patterns, I use a Monte Carlo randomized permutation resampling technique called the 'shuffle test' (Anagnostopoulos, Kumar, and Mahdian 2008). This test works through resampling the same population of participants many times, randomizing only the time of participation, and comparing distance-based metrics between the time-randomized (simulated) distribution and observed (empirical) distance-based metrics. Unlike the above regression analyses, the shuffle test, "controls" for the effects of individual level heterogeneity through the assumption that personal and property attributes typically remain unchanged over time. The simulated distribution therefore isolates the effect of order of participation by creating a counterfactual distribution of participation orderings likely to occur given no time dependence of participation location. The observed metric (for which we are interested in testing extent of time-dependence) is then compared to this simulated "shuffled" probability distribution. Significant departure of the observed metric from the simulated probability distribution indicates that empirical participation locations were dependent on the locations of previous participations.

Rejection of the null hypothesis indicates that the location of participation cannot be ruled out as independent from the timing of previous participants. The strength in resampling techniques improves the findings of the survey administered by the District by experimentally testing how spatial program growth may not merely be a function of personal or property characteristics, but also on exposure to previous participants. It also is able to isolate the effect of proximity to a previous participant from individual and neighborhood characteristics that are difficult to obtain data on, and which result in omitted variable bias and spatial autocorrelation. If all such individual-level variables could be measured and included in a regression, then the detection of spatial-temporal dependence in the shuffle test would be similar to identification of the estimated effects of spatial and temporal lags in regression.

I chose two metrics to represent exposure to GI: mean distance to closest previous program participant (DTC), and the number of previous participants within a 200m radius (R200). Proximity-based, time-dependent exposure pathways may include a resident observing a RiverSmart Homes sign while passing a previous participant's property, previous RiverSmart Homes participants talking about their installations to their neighbors, or a potential participant inquiring about a neighbors' landscape upgrades. For each year $t$ from 2010 to 2015, the set $G I_{t, \text { total }}$ includes all participants that have participated in the program at any time, from $t=2010$ to the 
Confidential manuscript in review at Journal of Environmental Planning and Management

current time, $t_{c u r}$. The set $G I_{t, \text { prev }}$ includes participants at time $t$ that participated between $\mathrm{t}=2010, \ldots, t_{\text {cur }-1}$. The set $G I_{t, \text { cur }}$ includes participants in $t_{\text {cur }}$ only. The simulated probability distribution is created by randomly assigning (with probability $=0.5$ ) each installation location in the set $G I_{t, \text { total }}$ to either $G I_{t, \text { cur }, i}$, or $G I_{t, p r e v, i}$, where $i$ indicates the $i^{\text {th }}$ simulation iteration set. Then, the two metrics, $\mathrm{DTC}_{\mathrm{i}}$ and $\mathrm{R} 200_{\mathrm{i}}$ are calculated using the actual geographic coordinates of participants with the random assignment for the $i^{\text {th }}$ iteration. The simulation is repeated for $i \epsilon(1, \ldots, N)$ to form the time-randomized simulated distribution, where $N$ is the total number of iterations (500). The observed metrics DTC and R200 for $t_{c u r}$ are compared to the simulated distributions for these metrics.

Figure 4 illustrates possible comparisons between the observed metrics and the metrics from a randomized iteration. For DTC, socially influenced clustering near previous participants would result in an observed mean distance that is on average less than mean distances from the time-randomized simulations. If there is no evidence of socially influenced clustering, then on average DTC should be about equal to the distances from the time-randomized simulations. Another type of timedependent patterning is if observed DTC are actually longer than the timerandomized simulations. This could occur if time-dependent outreach activities happening in specific neighborhoods outweigh neighbor-to-neighbor dynamics.

Figure 4 illustrates similar comparisons for the R200 metric. 
Confidential manuscript in review at Journal of Environmental Planning and Management

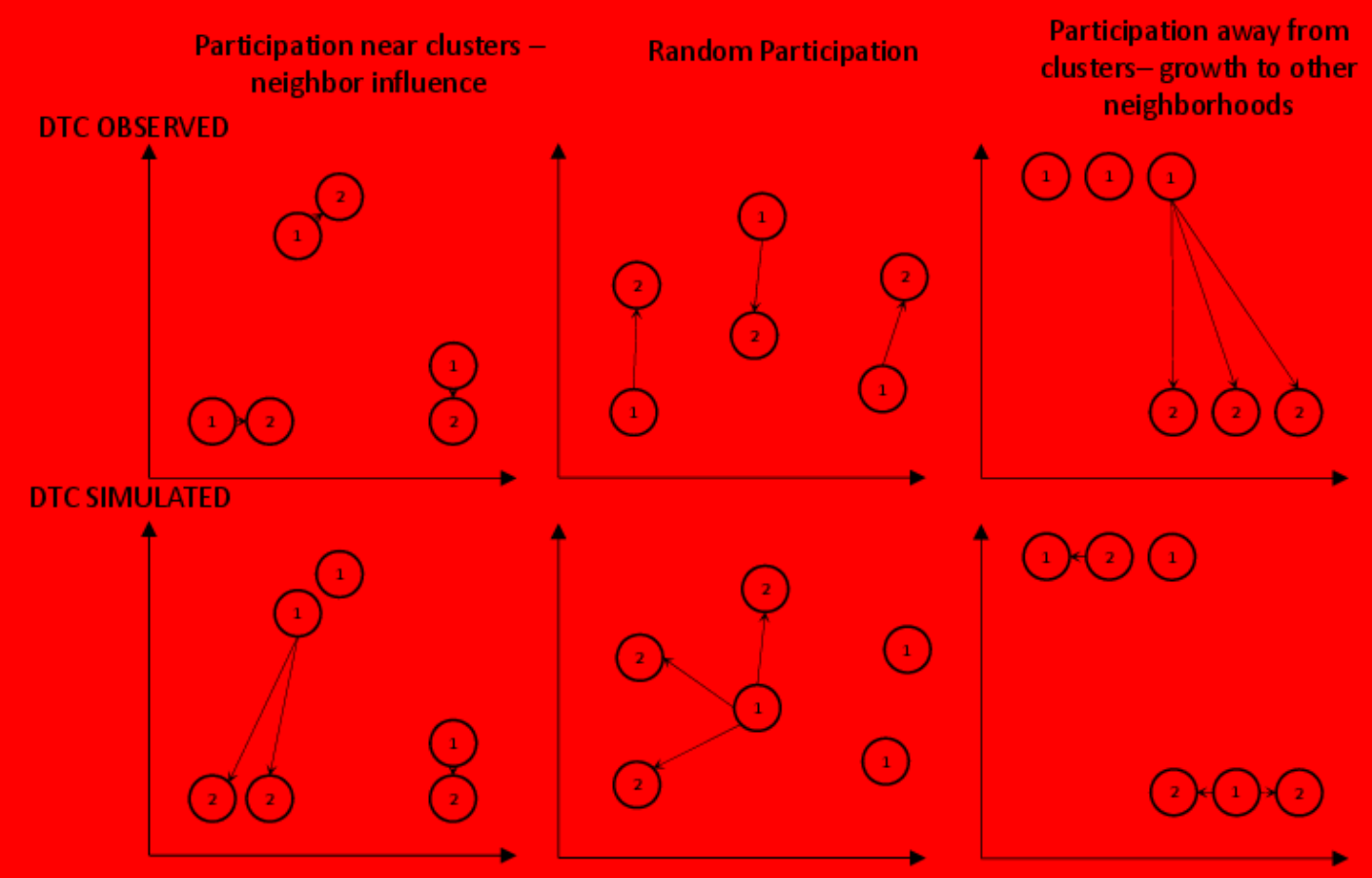

R200 OBSERVED
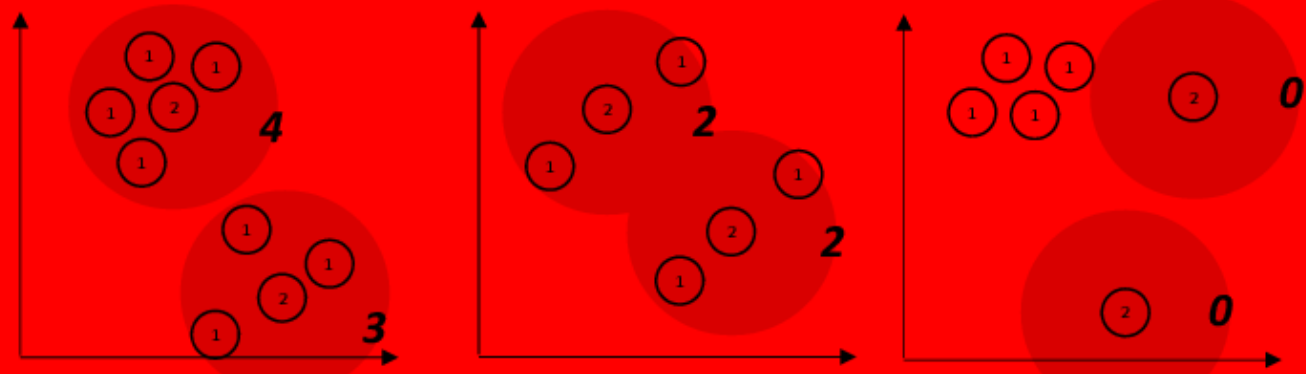

R200 SIMULATED
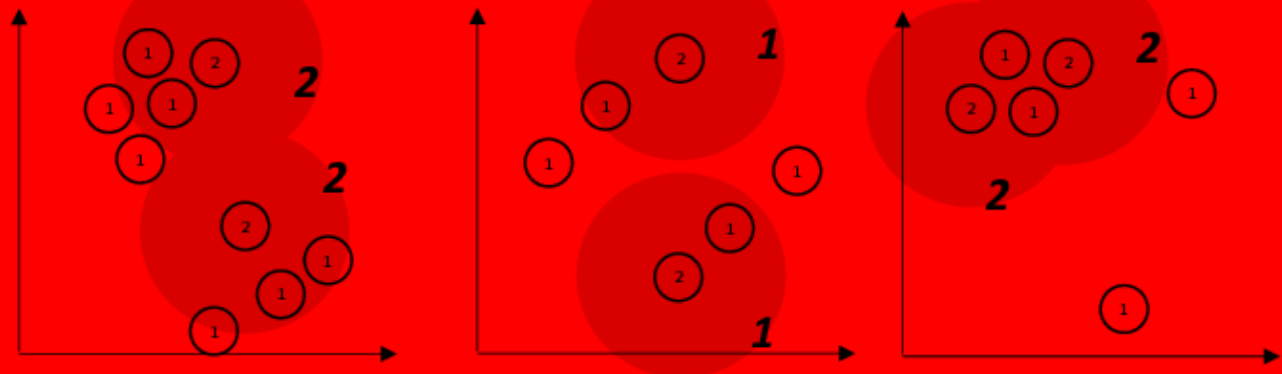
Confidential manuscript in review at Journal of Environmental Planning and Management

Figure 4. Conceptual illustration of observed metrics compared to a timerandomized iteration. Numbered circles represent the year of adoption 1, or 2 . The left-most column demonstrates the case of social influence clustering: the observed DTC metric is expected to be less than the average time-randomized simulation iteration, while the observed R200 metric is expected to be greater than the average time-randomized simulation iteration. The right-most column demonstrates the case of growth to distant neighborhoods: the observed DTC metric is expected to be greater than the average time-randomized simulation iteration, while the observed R200 metric is expected to be less than the average time-randomized simulation iteration. Gray circles represent the area within a given buffer radius of each year 2 participant. 


\section{Confidential manuscript in review at Journal of Environmental Planning and Management}

The choice of the time discretization (yearly) was chosen to help isolate the effect of information dissemination through the GI installations and previous participants themselves. The DOEE did provide promotional materials to community groups, non-profit organizations and at neighborhood-based fairs. These promotional activities would likely have a short-lived spatial effect on the spatial locations of participants. For example, in the days to weeks following a neighborhood promotional event, the DOEE confirmed seeing spikes in participants from that neighborhood. In this case, if the first participant reacting to such an activity had GI installed on her property and was followed by another participant in the neighborhood reacting to the same activity on his property several weeks later, then at the weekly scale, participant two might appear to have been "influenced" by his neighbor's (participant 1) installation. In fact both participants were responding to a location-based promotional activity. Discretizing time with longer intervals minimizes the effect of short-lived, spatial influences that increase participation. Table 2 highlights the spatial and temporal scales associated with participants' answers to the question "How did you find out about the RiverSmart Homes program?" that reported in the online survey (2014). Social interactions that are both spatially determined and likely to happen on longer (months to years) time scales that are dependent on spatial locations include interactions with neighbors or through prolonged information dissemination through a neighborhood or other spatially-based group.

\section{RESULTS}

\subsection{NEIGHBORHOOD CHARACTERISTICS AND OVERALL ADOPTION}

The results of the global regression are shown in Table 3. The full global model includes significant demographic and physical explanatory variables. The full model is able to account for over $50 \%$ of the variation in GI participation in census tracts (Adjusted $\mathrm{R}^{2}=0.53$ ). There is significant improvement in the explanatory power of the model when both sets of variables are included, but the likelihood ratio test (F-test) and Adjusted $\mathrm{R}^{2}$ values show that more explanatory power is derived from the demographic variables (Adjusted $R^{2}=0.35$ ) than the physical variables (Adjusted $\mathrm{R}^{2}=0.29$ ). The estimated coefficients in the full global model indicate that a $1 \%$ increase in the total number of households in a census tract is accompanied by a $2.2 \%$ increase in the number of GI installations, controlling for other factors. Higher mean percent imperviousness on residential parcels is associated with higher numbers of participants. However, the significance of a squared term for imperviousness indicates non-linearity. After reaching a turning point at $51.8 \%$ mean imperviousness, the effect of impervious area reverses and is associated with decreased participation. This indicates that higher levels of 


\section{Confidential manuscript in review at Journal of Environmental Planning and Management}

participation are found at intermediate levels of impervious surface area as a proportion of the property. Lower levels of participation are found at both the highest and lowest levels of site imperviousness. Increased numbers of renters is associated with decreased participation, confirming the results of previous empirical research on rain barrel adoption in Chicago (Ando and Freitas, 2011). Higher median incomes are also associated with increased participation, with $1 \%$ increase in median income associated with a $0.76 \%$ increase in number of participants. Census tracts that are over $80 \%$ white on average have $78.9 \%$ fewer participants than more diverse neighborhoods. Neighborhoods with higher levels of non-English speakers are also associated with higher numbers of participants, providing evidence corroborating the findings of previous surveys that find that non-White communities expressed greater support of stormwater management installations on private properties (Montalto et al., 2012; Baptiste et al., 2015). The standardized coefficients of the full global model show that the most influential explanatory variable was the total number of households in the census tract, followed by the dummy variable for whether or not the census tract was over $80 \%$ white.

A spatial autocorrelation test of the residuals of the full model using inverse weighted distances of the centroids of each census tract and Moran's I revealed evidence of spatial autocorrelation in the residuals of all three global models. The GWR models fit for each census tract capture the heterogeneity in estimated effect of each standardized variable accounting for spatial autocorrelation. As can be seen in Table 3, not all of the explanatory variables that are estimated as statistically significant at the alpha $=0.05$ level are estimated to have significant effects in all of the census-tract specific GWR estimates. The only variables that are estimated as statistically significant for all 172 DC census tracts are the log of the total number of households in the tract, the number of renters in the tract, and the dummy variable for whether the tract is $>80 \%$ white. The range of estimates of the variables bracket the global full model estimates but capture additional variability of effect distributed over space. Based on the results of the GWR, the most influential variables based on magnitude of the estimated standardized coefficients were the indicator for percent white $>80 \%$ (negative effect on adoption) and the average percent of tree canopy for all residential parcels within the tract (positive effect on adoption).

\subsection{SOCIAL INFLUENCE}

Evidence of significant time-dependent social influence was detected through both the DTC and R200 shuffle tests. Comparison between the simulated probability distribution and the observed DTC suggests that the effect of social influence between neighbors did not become dominant until 2014 (Figure 5a). From 2009 to 2010, there is a statistically significant evidence of time-dependency, but 2010 installations were located significantly further from 2009 installation than would be expected from a distribution of time-independent simulations ( $>99.9 \%$ percentile). After the first year of implementation, the observed DTC relative to the simulated probability distribution appears to reflect the right-most situation in Figure 4, where growth to distant areas outweighs proximate social influence of 
Confidential manuscript in review at Journal of Environmental Planning and Management

neighbors. Over time however, the influence of growth to distant areas is gradually outweighed by the influence of proximate neighbors.. By 2014, the observed DTC is significantly lower than what would be expected from a distribution of timeindependent simulations $(<0.1 \%$ percentile). This indicates that the growth of the program transitions from a dispersion dynamic to a clustering dynamic between 2009 and 2014, controlling for the overall increasing density of installations over time

The results from the R200 metric shuffle test support the finding that participation growth first occurred in distant areas after the first year (Figure 5b). The observed mean number of previous participants within a 200m radius of each 2010 participant was significantly lower than expected from a distribution of timeindependent simulations $(<0.1 \%$ percentile). This situation again reflects the rightmost situation shown in Figure 4. After three years however, this relationship reversed itself, and the observed mean number of previous participants within the $200 \mathrm{~m}$ radius of each 2012 participant (4.65) was significantly higher than expected from a distribution of time-independent simulations (mean $=3.89$ within $200 \mathrm{~m}$ radius; percentile $>99.9 \%$ ). This is more reflective of the left-most situation shown in Figure 4.

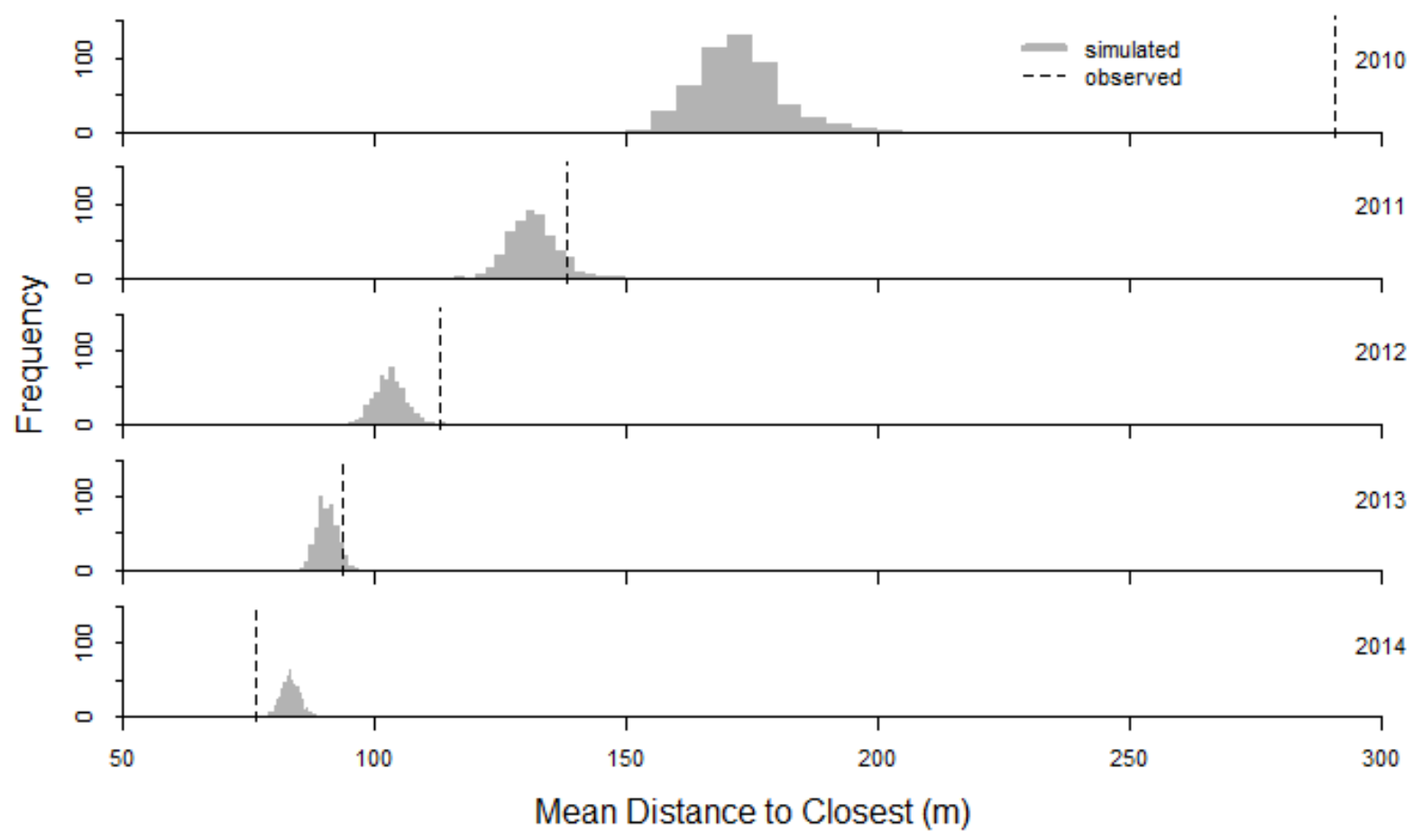


Confidential manuscript in review at Journal of Environmental Planning and Management

Figure 5a DTC comparison between simulated probability distribution and observed DTC (dashed line). 2010 percentile $>99.9 ; 2011$ percentile $=91.6 \%$; 2012 percentile $=99.6 \%$; 2013 percentile $<91.8 \%$; 2014 percentile $<0.1 \%$

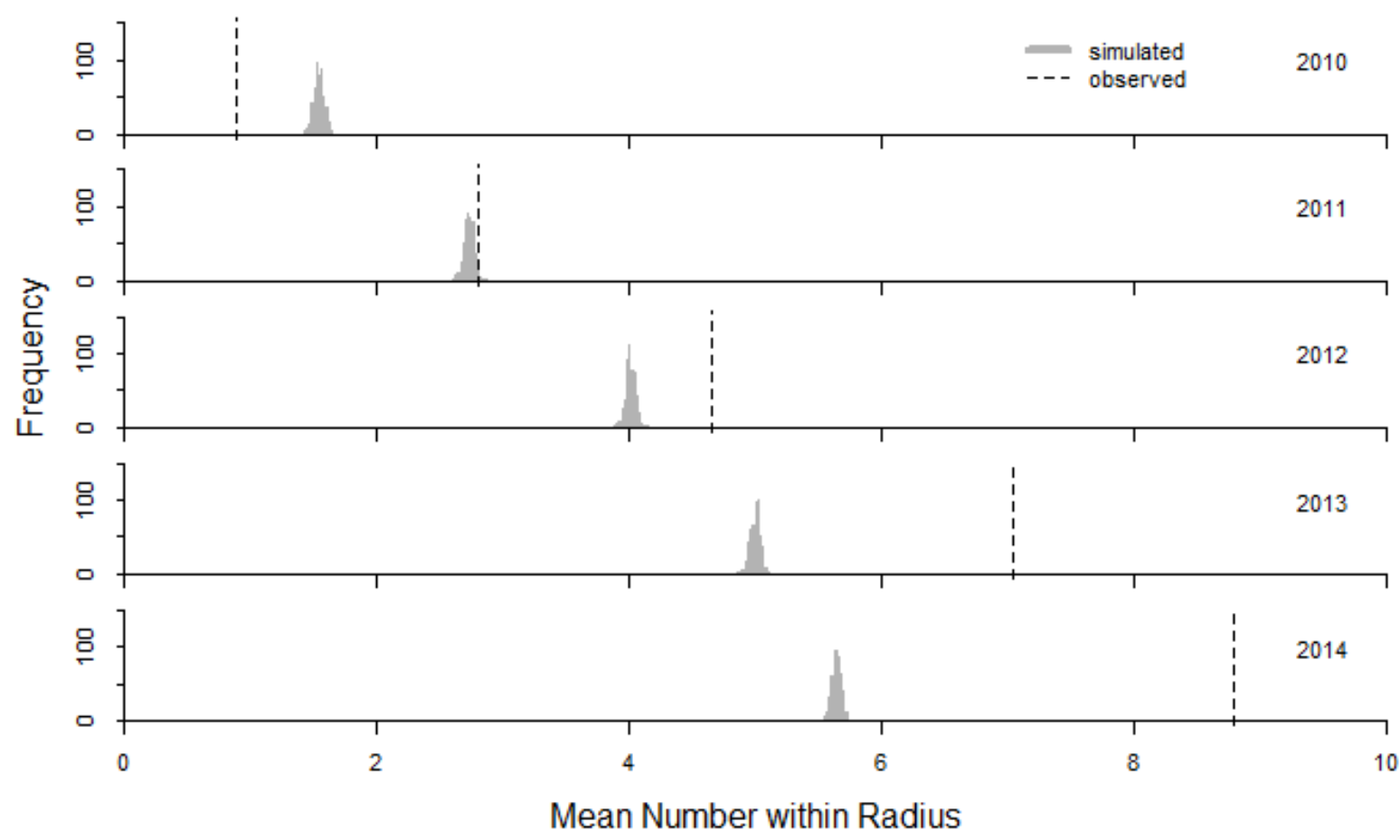

Figure 5b Comparison between simulated probability distribution and observed R200 (dashed line). 2010 percentile $<0.1 \% ; 2011$ percentile $=93.6 \% ; 2012$ percentile $>99.9 \%$; 2013 percentile $>99.9 \%$; 2014 percentile $>99.9 \%$

\section{DISCUSSION}

The regression results from this study confirm the survey results from other studies. Addressing spatial autocorrelation of residuals fit from a 'global' ordinary least squares regression model revealed how the magnitude of estimated effects of variables vary across the city. Further study of the variation of these effects may help identify reasons why some variables are more/less influential in certain neighborhoods. What is clear from the regression analysis however is that neighborhood demographic variables are able to explain more of the variation in participation than physical characteristics. Since the dependent variable was the log of the number of installations of any type of GI (rain barrels, rain gardens, bayscaping, shade trees or permeable pavement), residents willing to participate in the program are more likely to be able to choose an intervention compatible with the physical constraints of their properties. This would decrease the influence of physical factors compared to social factors. 


\section{Confidential manuscript in review at Journal of Environmental Planning and Management}

The results of the GWR estimates of standardized explanatory variables also revealed that adoption of GI may be driven for different reasons in different areas of the district. While the total number of households, the number of renters and a high proportion of white residents were factors that were significant in explaining the number of GI adoptions in every census tract, other factors, such as level of imperviousness, average parcel area, tree canopy cover, and median income were only statistically significant in explaining GI uptake in a subset of census tracts. Among census tracts were mean tree canopy cover was significant (62), tree canopy cover was the most influential variable explaining GI adoption in 60 of them.

Combining the findings of the regression analysis of overall participation with the findings of the shuffle tests allows for additional interpretation beyond similar studies that have sought to explain GI adoption using neighborhood characteristics. Instead of neighborhood characteristics reflecting the environmental attitudes, preferences of the participants, these characteristics could be more reflective of information flows and strength of social influence.

The findings of the shuffle tests demonstrated evidence that residents tended to participate close to previous participants even after controlling for increased density of the installations over time and for unobserved individual-level attributes that would cause people who live near each other to independently participate in the program. However, this pattern emerged only after a certain period of program growth to more distant areas. For the DTC metric, statistically significant proximate social influence was not evident until the fifth simulation year, compared to in the third simulation year for the R200 metric. An explanation for the difference in timing of this trend is the sensitivity of the DTC metric to distant outliers. Results of subsequent tests revealed, as expected, that as the buffer distance of the counts-within-radius metric is decreased (for example, R100), more years were necessary to detect statistically significant evidence of proximate social influence. As the radius was increased (for example to R300), evidence was apparent in the second year.

The patterns of social influence in a subsidized GI program detected in this research suggest that residential GI adoption can be viewed within stages. In the first stage (first 1-2 years of the program), early adopters contribute to the growth of the program throughout the city. In the second stage (years 2-4), the effect of locations of previous adopters begins to determine locations of subsequent adopters, outweighing growth to distant areas. In the third stage (years 3-5), adoptions by residents proximate to previous adopters becomes the dominant growth dynamic for the program.

\subsection{LIMITATIONS}

The main limitation of the shuffle test is the assumption that individuals' locationbased attributes are time-invariant. In reality, it is plausible that the locations of and demographics of decision makers are changing, and that this may be what is 


\section{Confidential manuscript in review at Journal of Environmental Planning and Management}

driving spatial-temporal dependence of GI adoptions. Systemic neighborhood demographic change over time is one example of a time-dependent change that might simultaneously drive GI adoption patterns. In the shuffle test, this pattern might appear like a neighbor's adoption 'influenced' a subsequent neighbor's adoption, when in fact one or both may have been driven by external trends. A time-dependent confounding factor includes real estate agents promoting the RiverSmart Homes program to their clients as a way to upgrade the property's landscaping. In this study these influences are assumed to be minimal compared to the influence between proximate neighbors spreading information and "displaying" their installations. However, the magnitude of such influences also likely vary across the city. Unfortunately, this study did not include sufficient observations to compare the results of shuffle tests from different census tracts. Compared to other models which seek to capture time dependency of information spread, including other resampling techniques (La Fond and Neville 2010), and panelbased regression (Geroski 2000), this study does not control for individual attributes, and therefore is unable to compare the relative impacts of social influence versus personal preferences on participation in voluntary GI programs.

What is unclear from this research therefore is whether normative-based peer pressure has resulted in changes in environmental attitude, or, if social influence is occurring through neighbors merely spreading information about the existence of the GI subsidy program. The choice of years as the time increment for the shuffle test is based on the assumption that other types of place-based program promotion would be expected to produce quick "bursts" of proximate participation as opposed to months-long or years long spatial-temporal dependence. However, I acknowledge that this logic is an imperfect proxy for conducting in-depth surveys for both how people learned of the program, and the spatial locations of their information sources.

Previous research has shown a tenuous relationship between knowledge of environmental function of GI installations and motivation to install GI (Roy et al. 2008; Londoño Cadavid and Ando 2013; Brown et al. 2016). Perhaps such a shift in the role of social influence would constitute a future "fourth phase" of voluntary residential adoption of GI. This fourth phase would then begin to appear like the eco-normative feedback mechanisms that have been shown to be influential for energy and water consumption "nudge" type initiatives (Allcott 2011; Jain et al. 2013; Schultz et al. 2016).

\section{CONCLUSION}

This research provides evidence that social influence between neighbors is a significant pathway for residents to find out about the River Smart Homes programs. Residential GI adoption shows evidence of positive social influence and that this influence results in clustered growth that outweighs growth to new areas after 2-3 years of program implementation. Showing that GI adoption is similarly responsive to peer influence for other environmental behaviors, such as water and 
Confidential manuscript in review at Journal of Environmental Planning and
Management
energy conservation and solar panel installations has implications for planners. The visibility of GI installation compared to other environmental behaviors makes it ideal to spread through space-based social networks as residents interact with each other and their local neighborhood environments. This suggests that planners should leverage the visibility and aesthetic of GI in high traffic areas to disseminate information about how to participate in voluntary programs and make positive impacts on the environment and enlist influential community members as "neighborhood ambassadors" for GI programs.

The findings of this study also demonstrate the importance of distinguishing between personal willingness to adopt GI, physical feasibility and social processes of information dissemination, as empirical correlation between low participation and certain social characteristics may be more attributed to limitations of program awareness than conscious preferences of residents. In addition to relevance for voluntary GI adoption programs, this finding is also useful for programs that rely on economic incentives as motivation for private adoption of GI. Social influence through neighborhood "ambassadors" and highly visible installations may increase initial awareness and confidence in this 'new technology' to spur participation in combination with economic or normative approaches to encouraging residential participation. 
Confidential manuscript in review at Journal of Environmental Planning and Management

\section{TABLES}

TABLE 1. Summary Statistics for Overall GI Adoption and Census Tract Attributes

\section{Green Infrastructure Adoptions (2009-2014)}

Total

Installations*

Rain Barrels

Rain Gardens

Bayscaping

Permeable

Pavement

Trees
0

0

0

0

0

0
14

7

1

2

0

3
28

14

3

4

1

7
215

107

30

37

6

Demographic

Variables

Total Households*

545

1519

1681

5375

786

Median Home

Value*

$\$$
133,970

Total Population

1025

0

1639

Pop $<$ High school

ed
44

0

0
75

15
1782

127

897

159

$\$$ $1,747,378$

3573

1427

5219

1264

14

70

9 
Confidential manuscript in review at Journal of Environmental Planning and Management

\begin{tabular}{|c|c|c|c|c|c|}
\hline $\begin{array}{l}\text { Pop with } \\
\text { Bachelor's Deg }\end{array}$ & 0 & 26 & 32 & 100 & 29 \\
\hline Percent in Poverty & $2 \%$ & $14 \%$ & $18 \%$ & $53 \%$ & $11 \%$ \\
\hline Median Income & $\begin{array}{l}\$ \\
14,813\end{array}$ & $\begin{array}{l}\$ \\
68,606\end{array}$ & $\begin{array}{l}\$ \\
74,053\end{array}$ & $\begin{array}{l}\$ \\
231,042\end{array}$ & $\begin{array}{l}\$ \\
41,489\end{array}$ \\
\hline $\begin{array}{l}\text { Unemployment } \\
\text { Rate }\end{array}$ & $0 \%$ & $10 \%$ & $12 \%$ & $40 \%$ & $9 \%$ \\
\hline Owner & 17 & 558 & 633 & 2099 & 399 \\
\hline Renter & 70 & 781 & 886 & 3360 & 559 \\
\hline $\begin{array}{l}\text { Percent Non- } \\
\text { English** }\end{array}$ & $0.00 \%$ & $0.08 \%$ & $0.15 \%$ & $1.34 \%$ & $0.24 \%$ \\
\hline
\end{tabular}

\section{Physical Variables}

\begin{tabular}{|c|c|c|c|c|c|}
\hline $\begin{array}{l}\text { Mean res parcel } \\
\text { area }(\mathrm{sf})^{*}\end{array}$ & 190 & 1203 & 1605 & 12666 & 1439 \\
\hline $\begin{array}{l}\text { Mean percent } \\
\text { impervious }\end{array}$ & $16 \%$ & $43 \%$ & $46 \%$ & $100 \%$ & $16 \%$ \\
\hline $\begin{array}{l}\text { Mean \% tree } \\
\text { canopy }\end{array}$ & $0 \%$ & $19 \%$ & $23 \%$ & $60 \%$ & $13 \%$ \\
\hline In MS4 (dummy) & 0 & 0 & 0.30 & 1 & 0.46 \\
\hline
\end{tabular}


Confidential manuscript in review at Journal of Environmental Planning and Management

Table 2 . Informational Pathways to RiverSmart Homes and Spatial-Temporal Scales

\begin{tabular}{|c|c|c|}
\hline $\begin{array}{l}\text { Reported } \\
\text { Means of } \\
\text { Informa- } \\
\text { tion about } \\
\text { RSHomes } \\
\end{array}$ & $\begin{array}{c}\text { Space Dependence Scale and } \\
\text { Example Process }\end{array}$ & $\begin{array}{c}\text { Time Dependence Scale and Ex- } \\
\text { ample Process }\end{array}$ \\
\hline $\begin{array}{l}\text { Friend, } \\
\text { Family, } \\
\text { Neighbor }\end{array}$ & $\begin{array}{l}\text { Close: Neighbors talking } \\
\text { Far: Friends across town talking }\end{array}$ & $\begin{array}{l}\text { Short: Talking about the program in } \\
\text { the days right after installation } \\
\text { Long: Talking about the program } \\
\text { months later when a neighbor notices } \\
\text { the rain barrel in the front yard }\end{array}$ \\
\hline Email & $\begin{array}{l}\text { Close: Neighborhood listserv } \\
\text { email blast } \\
\text { Far: City-wide affinity group list- } \\
\text { serv email blast }\end{array}$ & $\begin{array}{l}\text { Short: Response to email blast in } \\
\text { days following } \\
\text { Long: Repeated email blasts sent for } \\
\text { many months }\end{array}$ \\
\hline Internet & $\begin{array}{l}\text { Not Space Dependent. People } \\
\text { from across the city all can access } \\
\text { the Internet }\end{array}$ & $\begin{array}{l}\text { Not Time Dependent. People from } \\
\text { across the city can access content at } \\
\text { any time }\end{array}$ \\
\hline Print Media & $\begin{array}{l}\text { Not Space Dependent. For ex- } \\
\text { ample, newspapers distributed all } \\
\text { over city }\end{array}$ & $\begin{array}{l}\text { Short: Response to an advertisement } \\
\text { in the days after print }\end{array}$ \\
\hline $\begin{array}{l}\text { DOEE web- } \\
\text { site }\end{array}$ & $\begin{array}{l}\text { Not Space Dependent. For ex- } \\
\text { ample, people from across the city } \\
\text { all can access the Internet }\end{array}$ & $\begin{array}{l}\text { Not Time Dependent. People from } \\
\text { across the city can access content at } \\
\text { any time }\end{array}$ \\
\hline Flyer & $\begin{array}{l}\text { Close: Flyer posted at a local gro- } \\
\text { cery store seen by many neigh- } \\
\text { bors } \\
\text { Far: Flyer posted all over the city }\end{array}$ & $\begin{array}{l}\text { Short: Response to flyer in the days } \\
\text { to weeks that it is posted or distrib- } \\
\text { uted }\end{array}$ \\
\hline
\end{tabular}


Table 3. Global Regression and GWR of GI Adoption on Physical and Demographic Factors at the Census Tract Scale

Global Model: Demographic Factors Only

\begin{tabular}{|c|c|c|c|c|c|c|c|c|c|c|c|c|}
\hline & \multicolumn{6}{|c|}{ Only } & \multicolumn{6}{|c|}{ Global Model: Physical Factors Only } \\
\hline & beta & $b^{a}$ & s.e. & $p$ & & VIF & beta & $b^{a}$ & s.e. & $p$ & & VIF \\
\hline (Intercept) & $\begin{array}{r}18.4 \\
89 \\
2.94\end{array}$ & $\begin{array}{r}18.48 \\
9\end{array}$ & 3.872 & $\begin{array}{l}4 . \mathrm{E}- \\
06 \\
3 . \mathrm{E}-\end{array}$ & $* * *$ & & 7.6 & 7.6 & 3.1 & 0.017 & $*$ & \\
\hline log(Total Number of Households) & 3 & 7.051 & 0.610 & 06 & $* * *$ & 4.1 & -0.48 & -1.15 & 0.34 & 0.157 & $* *$ & 1.1 \\
\hline log(Average Parcel Area (sf)) & & & & & & & -0.97 & -1.84 & 0.28 & 8.E-04 & $\begin{array}{l}* \\
* *\end{array}$ & 1.3 \\
\hline Average Parcel Percent Impervious & & & & & & & 0.21 & 0.01 & 0.05 & 2.E-05 & $*$ & 32 \\
\hline $\begin{array}{l}\text { Square of Average Parcel Percent } \\
\text { Impervious } \\
\text { Average Percent Tree Canopy per }\end{array}$ & & & & & & & $\begin{array}{r}0.00 \\
2\end{array}$ & $\begin{array}{r}-1 . E- \\
06\end{array}$ & $\begin{array}{r}0.00 \\
05\end{array}$ & 4.E-06 & $\begin{array}{l}* * \\
*\end{array}$ & 33 \\
\hline Parcel & - & & & & & & 3.9 & 30.3 & 1.40 & $6 . \mathrm{E}-03$ & ** & 1.9 \\
\hline Number of Renters in Census Tract & $\begin{array}{r}0.00 \\
3 \\
-\end{array}$ & 0.000 & 0.000 & $\begin{array}{r}1 . \mathrm{E}- \\
10\end{array}$ & $* * *$ & 4.4 & & & & & & \\
\hline $\begin{array}{l}\text { Percent White }>80 \%(0,1) \\
\text { log(Median Income) } \\
\text { Percent non-English speaking }>0.3 \% \\
(0,1)\end{array}$ & $\begin{array}{r}1.03 \\
6 \\
0.19 \\
6 \\
0.91 \\
4\end{array}$ & $\begin{array}{r}-2.723 \\
0.339 \\
2.545\end{array}$ & $\begin{array}{l}0.400 \\
0.300 \\
0.359 \\
\end{array}$ & $\begin{array}{r}1 . \mathrm{E}- \\
02 \\
5 . \mathrm{E}- \\
01 \\
1 . \mathrm{E}- \\
02\end{array}$ & $\begin{array}{l}* * \\
* * * \\
* *\end{array}$ & $\begin{array}{l}1.5 \\
1.9 \\
1.1\end{array}$ & & & & & & \\
\hline $\begin{array}{l}\text { Adjusted } \mathrm{R}^{2} \\
\text { F stat }^{\mathrm{b}}\end{array}$ & & & $\begin{array}{l}.3543 \\
15 E-11\end{array}$ & & & & $\begin{array}{c}0.29 \\
06 \\
5.02 \\
E-14\end{array}$ & & & & & \\
\hline
\end{tabular}




\begin{tabular}{|c|c|c|c|c|c|c|c|c|c|c|}
\hline & \multicolumn{6}{|c|}{ Global Model: Full Model } & \multicolumn{4}{|c|}{ GWR Results (standardized) } \\
\hline & beta & $b^{a}$ & s.e. & $\mathrm{p}$ & & VIF & Min & Max & $\begin{array}{l}\text { Significant } \\
\text { Count }\end{array}$ & $\begin{array}{c}\text { Most In- } \\
\text { fluential } \\
\text { Count }\end{array}$ \\
\hline & $22.1^{-}$ & $22.13^{-}$ & & 3.E- & & & & & & \\
\hline (Intercept) & $\begin{array}{r}31 \\
2.24\end{array}$ & 1 & 4.150 & $\begin{aligned} 07 \\
4 . \mathrm{E}-\end{aligned}$ & $* * *$ & & -46 & 17 & 0 & 0 \\
\hline log(Total Number of Households) & 5 & 5.379 & 0.530 & 05 & *** & 4.3 & 0.37 & 0.62 & 172 & 0 \\
\hline log(Average Parcel Area (sf)) & $\begin{array}{r}0.35 \\
4 \\
0.20\end{array}$ & -0.669 & 0.247 & $\begin{array}{r}2 . \mathrm{E}- \\
01 \\
3 . \mathrm{E}-\end{array}$ & & 1.5 & -0.26 & -0.06 & 103 & 0 \\
\hline Average Parcel Percent Impervious & $\begin{array}{l}7 \\
-\end{array}$ & 0.013 & 0.043 & 06 & $* * *$ & 38 & -0.04 & 0.13 & 111 & 0 \\
\hline $\begin{array}{l}\text { Square of Average Parcel Percent } \\
\text { Impervious } \\
\text { Average Percent Tree Canopy per }\end{array}$ & $\begin{array}{r}0.00 \\
2 \\
1.76\end{array}$ & $\begin{array}{l}0.000 \\
13.65\end{array}$ & 0.000 & $\begin{array}{r}6 . \mathrm{E}- \\
08 \\
2 . \mathrm{E}-\end{array}$ & $* * *$ & 37 & $\begin{array}{r}0.00 \\
1\end{array}$ & $\begin{array}{r}0.000 \\
1\end{array}$ & 134 & 0 \\
\hline Parcel & 0 & 0 & 1.451 & 01 & & 3.1 & 0.52 & 2.4 & 60 & 60 \\
\hline Number of Renters in Census Tract & $\begin{array}{r}0.00 \\
2 \\
-\end{array}$ & 0.000 & 0.000 & $\begin{array}{r}3 . \mathrm{E}- \\
07\end{array}$ & $* * *$ & 5.1 & $\begin{array}{r}0.00 \\
2\end{array}$ & 0.001 & 172 & 0 \\
\hline Percent White $>80 \%(0,1)$ & $\begin{array}{r}1.55 \\
8 \\
0.76\end{array}$ & -4.093 & 0.374 & $\begin{array}{r}5 . \mathrm{E}- \\
05 \\
9 . \mathrm{E}-\end{array}$ & $* * *$ & 1.8 & -1.0 & -0.7 & 172 & 112 \\
\hline $\begin{array}{l}\text { log(Median Income) } \\
\text { Percent non-English speaking }>0.3 \%\end{array}$ & $\begin{array}{r}1 \\
0.71\end{array}$ & 1.316 & 0.289 & $\begin{array}{l}03 \\
2 . \mathrm{E}-\end{array}$ & $* *$ & 2.4 & -0.2 & 0.4 & 21 & 0 \\
\hline$(0,1)$ & 7 & 1.996 & 0.309 & 02 & $*$ & 1.1 & 0.1 & 0.4 & 11 & 0 \\
\hline $\begin{array}{l}\text { Adjusted } \mathrm{R}^{2} \\
\text { F stat }^{\mathrm{b}}\end{array}$ & & & .5289 & & & & & & & \\
\hline
\end{tabular}


$*$ significant at alpha $=0.05, * *$ significant at alpha $=0.01, * * *$ significant at alpha $=0.001$

a fully standardized coefficient estimate

b $F$ stat compared to full model

${ }^{c}$ the square of the average parcel percent impervious is included to capture a change in direction from positive to negative in the effect of this variable 


\section{FIGURE CAPTIONS (LIST)}

Figure 1. Cumulative number of installation and program participants over time

Figure 2. Density of all GI installations through the RiverSmart Homes Program from 2009 - 2014, overlaid on total population per census tract.

Figure 3. Survey responses from RiverSmart Homes participants to how they initially learned of the program.

Figure 4. Conceptual illustration of observed metrics compared to a timerandomized iteration. Numbered circles represent the year of adoption 1 , or 2 . The left-most column demonstrates the case of social influence clustering: the observed DTC metric is expected to be less than the average time-randomized simulation iteration, while the observed R200 metric is expected to be greater than the average time-randomized simulation iteration. The right-most column demonstrates the case of growth to distant neighborhoods: the observed DTC metric is expected to be greater than the average time-randomized simulation iteration, while the observed R200 metric is expected to be less than the average time-randomized simulation iteration. Gray circles represent the area within a given buffer radius of each year 2 participant.

Figure 5a DTC comparison between simulated probability distribution and observed DTC (dashed line). 2010 percentile $>99.9 ; 2011$ percentile $=91.6 \%$; 2012 percentile $=99.6 \% ; 2013$ percentile $<91.8 \%$; 2014 percentile $<0.1 \%$

Figure 5b Comparison between simulated probability distribution and observed R200 (dashed line). 2010 percentile $<0.1 \% ; 2011$ percentile $=93.6 \% ; 2012$ percentile $>99.9 \%$; 2013 percentile $>99.9 \%$; 2014 percentile $>99.9 \%$ 


\section{REFERENCES}

Allcott, Hunt. 2011. "Social Norms and Energy Conservation." Journal of Public Economics, Special Issue: The Role of Firms in Tax Systems, 95 (9-10): 1082-1095. doi:10.1016/j.jpubeco.2011.03.003.

Anagnostopoulos, Aris, Ravi Kumar, and Mohammad Mahdian. 2008. "Influence and Correlation in Social Networks." In Proceedings of the 14th ACM SIGKDD International Conference on Knowledge Discovery and Data Mining, 7-15. KDD '08. New York, NY, USA: ACM. doi:10.1145/1401890.1401897.

Ando, Amy W., and Luiz P. C. Freitas. 2011. "Consumer Demand for Green Stormwater Management Technology in an Urban Setting: The Case of Chicago Rain Barrels." Water Resources Research 47 (12): W12501. doi:10.1029/2011WR011070.

Anselin, Luc, and Daniel A. Griffith. 1988. "Do Spatial Effecfs Really Matter in Regression Analysis?" Papers in Regional Science 65 (1): 11-34. doi:10.1111/j.1435-5597.1988.tb01155.x.

Baptiste, April Karen, Catherine Foley, and Richard Smardon. 2015. "Understanding Urban Neighborhood Differences in Willingness to Implement Green Infrastructure Measures: A Case Study of Syracuse, NY." Landscape and Urban Planning 136 (April): 1-12. doi:10.1016/j.landurbplan.2014.11.012.

Benedict, Mark A., and Edward T. McMahon. 2006. Green Infrastructure: Linking Landscapes and Communities. Island Press.

Birch, Eugenie L., and Susan M. Wachter, eds. 2008. Growing Greener Cities: Urban Sustainability in the Twenty-First Century. Philadelphia: University of Pennsylvania Press.

Bivand, Robert. 2017. Geographically Weighted Regression. https://cran.rproject.org/web/packages/spgwr/vignettes/GWR.pdf.

Brown, Helen L., Darren G. Bos, Christopher J. Walsh, Tim D. Fletcher, and Sharyn RossRakesh. 2016. "More than Money: How Multiple Factors Influence Householder Participation in at-Source Stormwater Management." Journal of Environmental Planning and Management 59 (1): 79-97. doi:10.1080/09640568.2014.984017.

Castaneda, Marigold G., Carmelita P. Martinez, Rodilina Marte, and Banjo Roxas. 2015. "Explaining the Environmentally-Sustainable Consumer Behavior: A Social Capital Perspective." Social Responsibility Journal 11 (4): 658-676. doi:10.1108/SRJ-02-2014-0019.

DC Water. 2015. Long Term Control Plan Modification for Green Infrastructure.

de Graaf, Rutger, and Rutger van der Brugge. 2010. “Transforming Water Infrastructure by Linking Water Management and Urban Renewal in Rotterdam." Technological Forecasting and Social Change, Issue includes a Special Section on “Infrastructures and Transitions," 77 (8): 1282-1291. doi:10.1016/j.techfore.2010.03.011.

Diamond, Peter A, and Jerry A Hausman. 1994. "Contingent Valuation: Is Some Number Better Than No Number?" The Journal of Economic Perspectives 8 (4): $45-64$.

Geroski, P. A. 2000. “Models of Technology Diffusion.” Research Policy 29 (4-5): 603-625. doi:10.1016/S0048-7333(99)00092-X. 
Green, Olivia Odom, William D. Shuster, Lee K. Rhea, Ahjond S. Garmestani, and Hale W. Thurston. 2012. "Identification and Induction of Human, Social, and Cultural Capitals through an Experimental Approach to Stormwater Management." Sustainability 4 (8): 1669-1682. doi:10.3390/su4081669.

Grinblatt, Mark, Matti Keloharju, and Seppo Ikaheimo. 2004. Interpersonal Effects in Consumption: Evidence from the Automobile Purchases of Neighbors. Working Paper 10226. National Bureau of Economic Research. http://www.nber.org/papers/w10226.

Hoechle, Daniel. 2007. "Robust Standard Errors for Panel Regressions with CrossSectional Dependence." Stata Journal 7 (3): 281.

Hopper, Joseph R., and Joyce McCarl Nielsen. 1991. "Recycling as Altruistic Behavior Normative and Behavioral Strategies to Expand Participation in a Community Recycling Program." Environment and Behavior 23 (2): 195-220. doi:10.1177/0013916591232004.

Jaffe, Adam B., Richard G. Newell, and Robert N. Stavins. 2002. “Environmental Policy and Technological Change." Environmental and Resource Economics 22 (1-2): 41-70. doi:10.1023/A:1015519401088.

Jain, Rishee K., Rimas Gulbinas, John E. Taylor, and Patricia J. Culligan. 2013. “Can Social Influence Drive Energy Savings? Detecting the Impact of Social Influence on the Energy Consumption Behavior of Networked Users Exposed to Normative Eco-Feedback." Energy and Buildings 66 (November): 119127. doi:10.1016/j.enbuild.2013.06.029.

Keeley, Melissa, Althea Koburger, David P. Dolowitz, Dale Medearis, Darla Nickel, and William Shuster. 2013. "Perspectives on the Use of Green Infrastructure for Stormwater Management in Cleveland and Milwaukee." Environmental Management 51 (6): 1093-1108. doi:10.1007/s00267-013-0032-x.

La Fond, Timothy, and Jennifer Neville. 2010. "Randomization Tests for Distinguishing Social Influence and Homophily Effects." In Proceedings of the 19th International Conference on World Wide Web, 601-610. WWW'10. New York, NY, USA: ACM. doi:10.1145/1772690.1772752.

Larsen, Larissa, and Sharon L. Harlan. 2006. “Desert Dreamscapes: Residential Landscape Preference and Behavior." Landscape and Urban Planning 78 (12): 85-100. doi:10.1016/j.landurbplan.2005.06.002.

Londoño Cadavid, Catalina, and Amy W. Ando. 2013. "Valuing Preferences over Stormwater Management Outcomes Including Improved Hydrologic Function." Water Resources Research 49 (7): 4114-4125. doi:10.1002/wrcr.20317.

Mandarano, Lynn. 2011. “Clean Waters, Clean City: Sustainable Storm Water Management in Philadelphia." In Sustainability in America's Cities Creating the Green Metropolis, edited by Matthew I Slavin, 157-179. Washington: Island Press. http://dx.doi.org/10.5822/978-1-61091-028-6.

Mandarano, Lynn, and Kurt Paulsen. 2011. "Governance Capacity in Collaborative Watershed Partnerships: Evidence from the Philadelphia Region." Journal of Environmental Planning and Management 54 (10): 1293-1313. doi:10.1080/09640568.2011.572694.

Montalto, Franco A., Timothy A. Bartrand, Alexander M. Waldman, Katharine A. Travaline, Charles H. Loomis, Chariss McAfee, Juliet M. Geldi, Gavin J. Riggall, and Laureen M. Boles. 2013. “Decentralised Green Infrastructure: The Importance of Stakeholder Behaviour in Determining Spatial and 
Temporal Outcomes." Structure and Infrastructure Engineering 9 (12): 1187-1205. doi:10.1080/15732479.2012.671834.

Montalto, Franco, Christopher Behr, and Ziwen Yu. 2012. "Accounting for Uncertainty in Determining Green Infrastructure Cost-Effectiveness." In Economic Incentives for Stormwater Control, edited by Hale W. Thurston. Boca Raton, FL: CRC Press.

Nassauer, Joan Iverson, Zhifang Wang, and Erik Dayrell. 2009. "What Will the Neighbors Think? Cultural Norms and Ecological Design." Landscape and Urban Planning 92 (3-4): 282-292. doi:10.1016/j.landurbplan.2009.05.010.

Nolan, Jessica M., P. Wesley Schultz, Robert B. Cialdini, Noah J. Goldstein, and Vladas Griskevicius. 2008. "Normative Social Influence Is Underdetected." Personality and Social Psychology Bulletin 34 (7): 913-923. doi:10.1177/0146167208316691.

Parikh, Punam, Michael A. Taylor, Theresa Hoagland, Hale Thurston, and William Shuster. 2005. "Application of Market Mechanisms and Incentives to Reduce Stormwater Runoff.” Environmental Science \& Policy 8 (2): 133-144. doi:10.1016/j.envsci.2005.01.002.

Portney, Paul R. 1994. “The Contingent Valuation Debate: Why Economists Should Care." The Journal of Economic Perspectives, 3-17.

Rode, Johannes, and Alexander Weber. 2016. "Does Localized Imitation Drive Technology Adoption? A Case Study on Rooftop Photovoltaic Systems in Germany." Journal of Environmental Economics and Management 78 (July): 38-48. doi:10.1016/j.jeem.2016.02.001.

Roy, Allison H., Seth J. Wenger, Tim D. Fletcher, Christopher J. Walsh, Anthony R. Ladson, William D. Shuster, Hale W. Thurston, and Rebekah R. Brown. 2008. "Impediments and Solutions to Sustainable, Watershed-Scale Urban Stormwater Management: Lessons from Australia and the United States." Environmental Management 42 (2): 344-359. doi:10.1007/s00267-008-91191.

Sample, David J, James P Heaney, Leonard T Wright, Chi-Yuan Fan, Fu-Hsiung Lai, and Richard Field. 2003. "Costs of Best Management Practices and Associated Land for Urban Stormwater Control." Journal of Water Resources Planning and Management 129 (1): 59-68.

Schilling, Joseph, and Jonathan Logan. 2008. “Greening the Rust Belt: A Green Infrastructure Model for Right Sizing America's Shrinking Cities." Journal of the American Planning Association 74 (4): 451-466. doi:10.1080/01944360802354956.

Schultz, P. Wesley, Alyssa Messina, Giuseppe Tronu, Eleuterio F. Limas, Rupanwita Gupta, and Mica Estrada. 2016. "Personalized Normative Feedback and the Moderating Role of Personal Norms A Field Experiment to Reduce Residential Water Consumption." Environment and Behavior 48 (5): 686710. doi:10.1177/0013916514553835.

Sun, Ning, and Myrna Hall. 2013. “Coupling Human Preferences with Biophysical Processes: Modeling the Effect of Citizen Attitudes on Potential Urban Stormwater Runoff." Urban Ecosystems, March, 1-22.

Thurston, Hale W., Michael A. Taylor, Allison Roy, Matthew Morrison, William D. Shuster, Joshua Templeton, Matthew Clagett, and Heriberto Cabezas. 2008. "Applying a Reverse Auction to Reduce Stormwater Runoff." AMBIO: A Journal of the Human Environment 37 (4): 326-327. doi:10.1579/00447447(2008)37[326:AARATR]2.0.CO;2. 
Confidential manuscript in review at Journal of Environmental Planning and

Management

University of Vermont. 2011. "High-Resolution Land Cover for Washington DC.” US EPA, Office of Water. 2004. Report to Congress: Impacts and Control of CSOs and SSOs. EPA 833-R-04-001. EPA.

Valderrama, Alisa, and Larry Levine. 2012. Financing Stormwater Retrofits in Philadelphia and Beyond. NRDC.

Valderrama, Alisa, and Larry Levine. 2013. Creating Clean Water Cash Flows: Developing Private Markets for Green Stormwater Infrastructure in Philadelphia. R-13-01-A. NRDC.

Young, Robert F. 2011. "Planting the Living City: Best Practices in Planning Green Infrastructure-Results From Major U.S. Cities." Journal of the American Planning Association 77 (4): 368-381. doi:10.1080/01944363.2011.616996.

Zmyslony, Jean, and Daniel Gagnon. 1998. "Residential Management of Urban Front-Yard Landscape: A Random Process?" Landscape and Urban Planning 40 (4): 295-307. doi:10.1016/S0169-2046(97)00090-X. 